\title{
The Relationship Between Participation Involvement, Loyalty, and Behavior Intention of Marine Leisure Sports Participants
}

\author{
Nam-Jin Noh, M.D. student, Dept. of Marine Sports, Hanseo University, Seosan 31962, Korea. \\ *Chun-Ho Yang, Professor, Dept. of Marine Sports, Hanseo University, Seosan 31962, Korea, \\ healthyang@hanseo.ac.kr \\ ${ }^{*}$ Corresponding author
}

\begin{abstract}
This study was conducted to investigate the relationship between participation involvement, loyalty and the behavior intention of marine leisure sports participants, and the conclusions obtained through the research process are as follows. The subject of this study was set as a population of participants over age 20 who participated in marine leisure sports throughout Korea. For the sampling, a random sampling method was used among several non-probability sampling methods. The survey was distributed and answered using the self-evaluation method utilizing a questionnaire. A total of 384 data were used for the final analysis, excluding questionnaires that did not meet the purpose of the study. The results of it are as follows. First, participation involvement of marine leisure sports participants showed a positive correlation with all loyalty variables, while behavior intention partially showed a positive correlation. Second, all of the sub-variables of participation involvement had a statistically significant positive influence on all loyalty, including attitude loyalty and action loyalty. Third, among the subvariables of participation involvement, participation enjoyment had a positive influence on the noted reparticipation intention, and participation interest had a positive influence on the positive word of mouth variable. As a conclusion, it can be seen that participation involvement of marine leisure sports participants is an important variable influencing loyalty and behavior intention. Therefore, the participation involvement of participants participating in marine leisure sports was proved to be closely related to loyalty and behavior intention.
\end{abstract}

Keywords: Marine leisure sports, Involvement, Loyalty, Reparticipation, Intention.

Received: 08.12.2020 Accepted: 10.01.2021 $\quad$ Published: 06.02.2021

\section{INTRODUCTION}

Changes in personal values for pursuing leisure time are driving changes in the direction of people's leisure-oriented life. It is creating an environment where modern people can participate in active leisure activities at times other than the time required for survival, labor and study. In particular, in recent years, the desire to participate in activities that are more suited to their hobbies and personalities has been increasing by participating in more planned and systematic leisure activities rather than only accepting a passive leisure life. As such, the need for proactive and active leisure life of modern people is changing the concept of what is important to pursue over the course of a weekend. Weekends and the time allocated to leisure time on the weekend are veering away from the old perception that it's time to spend walking around the surroundings with family after work, or relaxing one's tired body at home. They are creating a new pattern of leisure that participates in leisure activities in the background of the natural environment to improve the quality of life through pursuit of more active and adventurous leisure time [1].

Active leisure participation has caused interest and desire for outdoor activities rather than for the participation of sports using indoor activities. Among these patterns of active participation leisure, leisure sports where people enjoy sports by taking advantage of nature are attracting attention. In particular, as a nature-friendly leisure sports activity that maintains a harmonious and friendly relationship between nature and humans, it is growing as a sport that is in the spotlight by modern people [2]. Among nature friendly leisure sports, marine leisure sports is a voluntary sports activity using equipment in natural environments such as rivers and seas. Marine leisure sports are leisure activities that bring fun and happiness not only to individuals, but also to family, business associates, friends, and hobbyists. Therefore, it is rapidly emerging as proactive and active leisure activities.

In Korea, marine leisure sports have recently attracted a lot of attention mainly from young people. This tendency seems to originate from being able to coexist with nature while enjoying adventure and challenge, which are essential characteristics of the high enjoyment of participating in marine leisure 
sports.

Marine leisure sports is defined as a concept that includes competitive, hobbyist, or systematic, unstructured sports type marine sports and leisure type marine sports activities, that are performed using various motorized and non-motorized equipment in rivers and seas. In addition, according to the [3], marine leisure sports are classified into motorized and non-motorized marine leisure activities depending on whether or not a motor thruster with a horsepower of $5 \mathrm{hp}$ or more is mounted on a water leisure device. Looking at the representative marine leisure sports, there are motor boats, cruise yachts, and water motorcycles as motorized marine leisure sports, and water skiing, canoeing, and rafting which are considered as non-motorized sports. Scuba diving is another type of event that is done by exploring submerged in the sea.

The increasing population of marine sports and the interests of modern people interested in pursuing sports in marine leisure sports-related fields utilizing marine resources continue to grow. As a result, the popularization of marine leisure sports and the foundation for fostering high value-added industries are being laid. As a way of achieving these goals, there are plans to expand the infrastructure for marine leisure sports cultural settlement and revitalization, and plans to expand infrastructure through support for the construction of yacht schools and network construction between marina ports. In addition, local governments are showing interest in building infrastructure related to marine leisure sports to allow greater public participation in these sports activities. Although much effort has been made by the central government and local governments, the development of marine leisure sports requires the gathering of the opinions of various professional groups. Through the enactment of comprehensive laws through professional groups, systematic education, and the establishment of a mutual cooperation system amongst related associations, the establishment of an integrated information system through the development of various content, it is possible to provide various information programs necessary for the use of safe and pleasurable marine leisure sports open to community participation.

In order to accelerate the popularization of marine leisure sports, continuous prior studies have been conducted. However, most of the existing studies have been focused on policy or operational problems for the commercialization of marine leisure sports [4]. In fact, studies related to the analysis of domestic marine leisure sports that have been carried out since mid-2000s conducted studies on various aspects of psychological, economic, and physical factors perceived by members participating in marine leisure sports. These studies are showing limitations in diagnosing the policy problems of marine leisure sports and finding ways to improve them. In view of the results of the studies so far, macroscopic and comprehensive studies of participants directly participating in marine leisure sports are considered to be incomplete. Therefore, it is necessary to study the variables of participation involvement, loyalty, and behavior intention, focusing on participants, the main consumers of marine leisure sports activities.

Participation involvement, a factor influencing consumer behavior, can be said to be the degree of consumer participation interest in an event. In other words, participation involvement refers to the level of personal importance or interest to participate by being perceived by a stimulus in a specific situation. In the sports industry market, participation involvement can be used as a variable to subdivide the market, who introduced the concept of involvement for the first time in the field of marketing and consumer behavior, said that the customer's attitude and behavior appear differently according to the degree of involvement, and that it is needed to establish a marketing strategy accordingly. In addition, a study by [5] argued that involvement positively affects psychological loyalty and eventually increases behavioral loyalty. As such, involvement can be regarded as a major variable affecting consumer behavior. For this reason, research on leisure and sports-related involvement was mainly conducted on sports activities taking place in the United States. They focus on establishing the concept of involvement and developing measurement tools to analyze participation and other factors. This is because involvement, especially participation involvement, shows the intention to continuously participate through the importance and utilization of marine leisure sports participants. In addition to involvement, behavior intention is one of the important variables for the continuous participation of marine leisure sports participants. Looking at previous studies related to behavioral intention so far, they were focused on research related to sports facilities such as outdoor / screen golf driving ranges as well as fitness centers . It was said that high satisfaction with the service and physical environment of sports facilities had a significant effect on re-entry intentions, loyalty, spectator persistence, and participation intention. Despite these previous studies, studies on loyalty and behavior intention of participants in marine leisure sports have not been conducted in detail according to a literature search. Therefore, this study aims to provide basic data for qualitative development and activation of marine leisure sports for participants who are participating in rapidly diversifying marine leisure sports, and for this, a study on participation involvement, loyalty and behavior intention of marine leisure sports participants was conducted and analyzed. 


\section{Materials and Methods}

\subsection{Subjects}

To begin with, the subject of this study was set as a population of participants over age 20 who participated in marine leisure sports throughout Korea. For the sampling, a random sampling method was used among non-probability sampling methods. The survey was answered using the selfevaluation method using a questionnaire. A total of 384 data were used for the final analysis, excluding questionnaires that did not meet the purpose of the study. [Table 1] shows the general characteristics of the study subjects.

Table 1 General characteristics of subjects

\begin{tabular}{llll}
\hline Variable & Classification & Frequency (n) & Percentage (\%) \\
\hline \multirow{2}{*}{ Gender } & male & 247 & 64.3 \\
& female & 137 & 35.7 \\
\hline \multirow{3}{*}{ Age } & $20 \mathrm{~s}$ & 98 & 25.5 \\
& $30 \mathrm{~s}$ & 101 & 26.3 \\
& $40 \mathrm{~s}$ & 117 & 30.5 \\
& 50s and over & 68 & 17.7 \\
Income & less than 1 mil. won & 61 & 15.9 \\
& 1m - less than 2m & 69 & 18.0 \\
& 2m-less than 3m & 69.6 \\
& 3m- less than 4m & 79 & 16.9 \\
& 4m- less than 5m & 65 & 18.2 \\
& 5m or over & 70 & 10.4 \\
\hline \multirow{4}{*}{ Event } & Cruise yacht & 40 & 21.9 \\
& Skin scuba & 84 & 18.6 \\
& Wind surfing & 72 & 13.3 \\
& Water ski & 51 & 15.6 \\
\hline & Canoe/kayak & 60 & 21.5 \\
& others & 82 & 9.1 \\
\hline
\end{tabular}

\subsection{Tools}

\subsubsection{Participation involvement}

The participation involvement scale used in the survey were items edited and adapted to suit the study based on items used by [5], [6] which were adapted by [3] using items developed by [17]. The sub variables of participation involvement consisted of participation enjoyment (4 items), participation importance (3 items), and participation interest (3 items). The measurement method of each item consisted of the Likert scale, 'Strongly disagree 1 point' to 'Strongly agree 5 points'.

\subsubsection{Loyalty}

The loyalty scale used in the survey was based on Kim [7] and items used by [5, 8] were modified and adapted to suit the purpose of the study. The sub-variables of loyalty consisted of attitude loyalty ( 4 items) and action loyalty ( 4 items). The measurement method of each item consisted of the Likert scale, 'Strongly disagree 1 point' to 'Strongly agree 5 points'.

\subsubsection{Behavior intention}

The behavior intention scale used in the survey was based on [9] and items used by [6, 9] and [10] 
were modified and adapted to suit the purpose of the study. The sub-variables of behavior intention consisted of reparticipation intention ( 3 items) and positive word of mouth (3 items). The measurement method of each item consisted of the Likert scale, 'Strongly disagree 1 point' to 'Strongly agree 5 points'.

\subsection{Validity and Reliability}

\subsubsection{Participation involvement}

Table 2 Results of validity and reliability analysis of involvement

\begin{tabular}{lllll}
\hline Q No. & Participation interest & Participation importance & Participation involvement & $\mathrm{h}^{2}$ \\
\hline Q 06 & $\mathbf{. 8 3 6}$ & -.051 & .044 & .615 \\
Q 05 & $\mathbf{. 8 2 4}$ & -.007 & .105 & .315 \\
Q 04 & $\mathbf{. 7 8 2}$ & .044 & .034 & .794 \\
Q 07 & $\mathbf{. 7 6 8}$ & .091 & .045 & .751 \\
Q 08 & .051 &. $\mathbf{8 1 7}$ & .183 & .690 \\
Q 10 & .022 & $\mathbf{8 1 3}$ & -.019 & .704 \\
Q 09 & -.016 &. $\mathbf{7 9 6}$ & .038 & .600 \\
Q 02 & .004 & -.022 &. $\mathbf{8 9 1}$ & .704 \\
Q 03 & .068 & .039 &. $\mathbf{8 6 3}$ & .635 \\
Q 01 & .062 & .322 & .456 & .662 \\
\hline Eigenvalue & 2.728 & 2.174 & 1.569 & \\
Variance $\%$ & 27.281 & 21.735 & 15.687 & \\
Cumulative $\%$ & 27.281 & 49.016 & 64.703 & \\
\hline Reliability & .705 & .756 & .694 & \\
\hline
\end{tabular}

$\mathrm{KMO}=.688, \chi^{2}=1123.480, \mathrm{df}=45, p=.001$

The Bartlett unit matrix of participation involvement was 1123.480, the significant probability was .001 , and the KMO index was .688, and selection of variables was appropriate. For participation involvement, 3 factors were extracted as a result of factor analysis of 10 items, and it was found that about $64.7 \%$ of the total variance was explained. The loading of participation enjoyment, a subvariables of participation interest was found to be $.768 \sim .836$. The loading of participation importance was .796 .817, and the loading of participation involvement was $.456 \sim .891$. The reliability values of participation involvement were found to be participation enjoyment .705, participation importance .756 , and participation interest 694 .

\subsubsection{Loyalty}

Table 3 Results of validity and reliability analysis of loyalty

\begin{tabular}{llll}
\hline Q No. & Attitude loyalty & Action loyalty & $\mathrm{h}^{2}$ \\
\hline Q 02 & $\mathbf{8 8 7}$ & .180 & .754 \\
Q 03 & $\mathbf{. 8 8 0}$ & .220 & .820 \\
Q 01 & $\mathbf{. 8 5 0}$ & .181 & .823 \\
Q 04 & $\mathbf{. 8 3 9}$ & .201 & .745 \\
Q 06 & .142 &. $\mathbf{8 4 4}$ & .707 \\
Q 05 & .225 &. $\mathbf{8 1 0}$ & .733 \\
Q 08 & .123 &. $\mathbf{8 0 0}$ & .673 \\
Q 07 & .268 &. $\mathbf{7 7 5}$ & .655 \\
\hline Eigenvalue & 4.254 & 1.656 & \\
Variance $\%$ & 53.180 & 20.703 & \\
Cumulative $\%$ & 53.180 & 73.883 & \\
\hline Reliability & .637 & .680 & \\
\hline
\end{tabular}

$\mathrm{KMO}=.840, \chi^{2}=1821.515, \mathrm{df}=28, p=.001$ 
The Bartlett unit matrix of loyalty was 1821.515 , the significant probability was .001 , and the KMO index was .840, and selection of variables was appropriate. For loyalty, 2 factors were extracted as a result of factor analysis of 8 items, and it was found that about $73.8 \%$ of the total variance was explained. The loading of attitude loyalty, a sub-variables of loyalty, was found to be $.839 \sim .887$, and loading of action loyalty was $.775 \sim .844$. The loyalty reliability values were attitude loyalty .637 and action loyalty .680 .

\subsubsection{Behavior intention}

Table 4 Results of validity and reliability analysis of behavior intention

\begin{tabular}{llll}
\hline Q No. & \multicolumn{1}{c}{ Reparticipation intention } & Positive word of mouth & $\mathrm{h}^{2}$ \\
\hline Q 02 & $\mathbf{. 8 6 8}$ & -.015 & .585 \\
Q 03 & $\mathbf{. 8 3 5}$ & -.001 & .658 \\
Q 01 &. $\mathbf{8 0 3}$ & -.003 & .627 \\
Q 04 & .049 & $\mathbf{. 8 1 0}$ & .754 \\
Q 06 & .019 & $\mathbf{7 9 2}$ & .697 \\
Q 05 & -.076 & $\mathbf{. 6 9 2}$ & .645 \\
\hline Eigenvalue & 2.105 & 1.762 & \\
Variance \% & 35.087 & 29.360 & \\
Cumulative \% & 35.087 & 64.447 & \\
\hline Reliability & .715 & .853 & \\
\hline
\end{tabular}

KMO $=.667, \chi^{2}=499.528, \mathrm{df}=15, p=.001$

The Bartlett unit matrix of behavior intention was 499.528 , the significant probability was .001 , and the KMO index was .667, and selection of variables was appropriate. For behavior intention, 2 factors were extracted as a result of factor analysis of 6 items, and it was found that about $64.4 \%$ of the total variance was explained. The loading of reparticipation intention, a sub-variables of behavior intention, was found to be $.803 \sim .868$, and the loading of positive word of mouth was $.692 \sim .810$. The reliability values of behavior intention were reparticipation intention .715 and positive word of mouth 853 .

\subsection{Data Processing}

Through this process, a SPSS (ver 21.0) statistics program was used for the collected data. The data collected according to the purpose of the study were 384 copies except for the surveys determined not to be appropriate for the study. The collected data was subjected to frequency analysis, exploratory factor analysis, and reliability analysis to confirm normal distribution, validity, and reliability. A correlation analysis was performed to find the relationship between variables, and a multiple regression analysis was performed to find the causal relationship between variables. Here, the significance level was set to $\alpha=.05$.

\section{Results}

3.1. Correlation Between Participation Involvement, Loyalty, and Behavior Intention of Marine Leisure Sports Participants

Table 5 Correlation between participation involvement, customer loyalty and reparticipation intention

\begin{tabular}{lllllll}
\hline Variable & $\mathrm{A}$ & $\mathrm{B}$ & $\mathrm{C}$ & $\mathrm{D}$ & $\mathrm{E}$ & $\mathrm{H}$ \\
\hline Participation interest & - & & & & & \\
Participation importance & .049 & - & & & & \\
Participation involvement & $.107^{*}$ & $.197^{* * *}$ & - & & & \\
Attitude loyalty & $.198^{* * *}$ & $.249^{* * *}$ & $.564^{* * *}$ & - & & \\
Action loyalty & $.159^{* *}$ & $.180^{* * *}$ & $.350^{* * *}$ & $.439^{* * *}$ & - &
\end{tabular}




\begin{tabular}{llllllll} 
Reparticipation intention & $.645^{* * *}$ & .080 & .064 & $.113^{*}$ & $.139^{* *}$ & - \\
Positive word of mouth & .013 & .085 & $.128^{*}$ & .059 & .013 & .011 & - \\
\hline
\end{tabular}

${ }^{* * *} p<.001,{ }^{* *} p<.01,{ }^{*} p<.05$

As a result of examining the correlation between participation involvement and loyalty and behavior intention of marine leisure sports participants, participation enjoyment showed positive correlation in attitude loyalty $(\mathrm{r}=.198, \mathrm{p}<.001)$, action loyalty $(\mathrm{r}=.159, \mathrm{p}<.01)$, and reparticipation intention $(\mathrm{r}=.645, \mathrm{p}<.001)$. Participation importance showed positive correlation in attitude loyalty $(\mathrm{r}=.249, \mathrm{p}<.001)$ and action loyalty $(\mathrm{r}=.180, \mathrm{p}<.001)$. Participation interest showed positive correlation in attitude loyalty $(\mathrm{r}=.564, \mathrm{p}<.001)$, action loyalty $(\mathrm{r}=.350, \mathrm{p}<.001)$, and positive word of mouth $(\mathrm{r}=.128, \mathrm{p}<.05)$.

\subsection{Effects of Participation Involvement of Marine Leisure Sports Participants on Loyalty}

\subsubsection{Effects of participation involvement on attitude loyalty}

Table 6 The effect of participation involvement on attitude loyalty

\begin{tabular}{lllllll}
\hline & $\mathrm{B}$ & $\mathrm{SE}$ & $\beta$ & $t$ & Tolerance & VIF \\
\hline (Constant) & .257 & .272 & & .943 & & \\
Participation interest & .144 & .044 & .135 & $3.254^{* * *}$ & .988 & 1.012 \\
Participation importance & .169 & .051 & .139 & $3.304^{* * *}$ & .960 & 1.041 \\
Participation involvement & .610 & .049 & .523 & $12.384^{* * *}$ & .952 & 1.051 \\
\hline
\end{tabular}

$\mathrm{F}=70.045^{* * *}, \mathrm{R}^{2}=.356$, Corrected $\mathrm{R}^{2}=.351$

$* * * p<.001$

Participation involvement had a statistically significant effect on attitude loyalty $(\mathrm{F}=70.045, \mathrm{p}<.001)$, and the explanatory power was about $35.6 \%\left(\mathrm{R}^{2}=.356\right)$ of the total variance. Looking at the Beta value, the relative influence of participation involvement on attitude loyalty, positive influence was found in participation enjoyment $(\beta=.135, \mathrm{p}<.001)$, participation importance $(\beta=.139, \mathrm{p}<.001)$, and participation interest $(\beta=.523, \mathrm{p}<.001)$.

\subsubsection{Effects of participation involvement on action loyalty}

Table 7 The effect of participation involvement on action loyalty

\begin{tabular}{lllllll}
\hline & $\mathrm{B}$ & $\mathrm{SE}$ & $\beta$ & $t$ & Tolerance & VIF \\
\hline (Constant) & 2.131 & .262 & & $8.138^{* * *}$ & & \\
Participation interest & .107 & .043 & .119 & $2.505^{*}$ & .988 & 1.012 \\
Participation importance & .114 & .049 & .112 & $2.319^{*}$ & .960 & 1.041 \\
Participation involvement & .308 & .047 & .315 & $6.501^{* * *}$ & .952 & 1.051 \\
\hline
\end{tabular}

$\mathrm{F}=22.264^{* * *}, \mathrm{R}^{2}=.149$, Corrected $\mathrm{R}^{2}=.143$

$* * * p<.001, * p<.05$

Participation involvement had a statistically significant effect on action loyalty $(\mathrm{F}=22.264, \mathrm{p}<.001)$, and the explanatory power was about $14.9 \%\left(\mathrm{R}^{2}=.149\right)$ of the total variance. Looking at the Beta value, the relative influence of participation involvement on action loyalty, positive influence was found in participation enjoyment $(\beta=.119, \mathrm{p}<.05)$, participation importance $(\beta=.112, \mathrm{p}<.05)$, and participation interest $(\beta=.315, \mathrm{p}<.001)$.

\subsection{Effects of Participation Involvement of Marine Leisure Sports Participants on Behavior Intention}

\subsubsection{Effects of participation involvement on reparticipation intention}


Table 8 The effect of participation involvement on reparticipation intention

\begin{tabular}{lllllll}
\hline & $\mathrm{B}$ & $\mathrm{SE}$ & $\beta$ & $t$ & Tolerance & VIF \\
\hline (Constant) & 1.573 & .203 & & $7.749^{* * *}$ & & \\
Participation interest & .541 & .033 & .644 & $16.358^{* * *}$ & .988 & 1.012 \\
Participation importance & .049 & .038 & .051 & 1.274 & .960 & 1.041 \\
Participation involvement & .014 & .037 & .015 & -.373 & .952 & 1.051 \\
\hline $\mathrm{F}=91.109 * * *, \mathrm{R}^{2}=.418$, Corrected $\mathrm{R}^{2}=.414$ & & & & \\
\hline$* * * p<.001$ &
\end{tabular}

Participation involvement had a statistically significant effect on reparticipation intention ( $F=91.109$, $\mathrm{p}<.001)$, and the explanatory power was about $41.8 \%\left(\mathrm{R}^{2}=.418\right)$ of the total variance. Looking at the Beta value, the relative influence of participation involvement on reparticipation intention, positive influence was found as an important factor in participation significance $(\beta=.644, \mathrm{p}<.001)$.

\subsubsection{Effects of participation involvement on positive word of mouth}

Table 9 The effect of participation involvement on positive word of mouth

\begin{tabular}{lllllll}
\hline & $\mathrm{B}$ & $\mathrm{SE}$ & $\beta$ & \multicolumn{2}{c}{ Tolerance } & VIF \\
\hline (Constant) & 4.481 & .296 & & $15.127^{* * *}$ & & \\
Participation interest & .002 & .048 & .002 & .045 & .988 & 1.012 \\
Participation importance & .066 & .056 & .062 & 1.191 & .960 & 1.041 \\
Participation involvement & .120 & .054 & .116 & $2.236^{*}$ & .952 & 1.051 \\
\hline
\end{tabular}

$\mathrm{F}=2.612^{*}, \mathrm{R}^{2}=.020$, Corrected $\mathrm{R}^{2}=.012$

$* * * p<.001$

Participation involvement had a statistically significant effect on positive word of mouth $(\mathrm{F}=2.612$, $\mathrm{p}<.05)$, and the explanatory power was about $0.2 \%\left(\mathrm{R}^{2}=.020\right)$ of the total variance. Looking at the Beta value, the relative influence of participation involvement on positive word of mouth, positive influence was found in regard to the participation interest $(\beta=.116, p<.05)$.

\section{Discussion}

This study was conducted to investigate the relationship between participation involvement and loyalty and behavior intention of marine leisure sports participants. Based on the results of this study, it will be discussed as follows.

As a result of this study, participation correlation of marine leisure sports participants showed the presence of a positive correlation in all loyalty, while partial positive correlation in behavior intention. As a result of conducting multiple regression analysis to examine this in detail, it was found that all of the sub-variables of participation involvement had a statistically significant statistical impact on both attitude loyalty and action loyalty. Also, in regard to behavior intention, participation significance had a positive influence on reparticipation intention, and participation interest had a positive influence on positive word of mouth.

In fact, participation involvement is information related to important values or motivations and is described as the relevance of an object based on an individual's needs, values, or interests [11]. It is argued that individual involvement and attitude are considered to be separate factors, and attitudes toward products and services can be formed differently depending on involvement. In other words, if the level of involvement with customers is low, whereby they do not put much effort into information exploration, and if the level of involvement is high, more detailed information about the product is searched by the customers seeking information on products. Therefore, involvement plays an important role in the formation of a basic attitude toward products and services. In addition, the perceived pleasure of the purchased product or service that is expected to be received plays an important role in the consumer's attitude formation process. When the involvement is high, the possibility of receiving information is reduced, but when it is accepted, the pleasure is perceived greatly. On the other hand, if the involvement is low, the scope of information acceptance is widened, but the pleasure can be greatly reduced. In this context, reparticipation intention is formed after participation in sports activities by 
those who are not interested in sports activities but people with high interest can be seen to develop attitudes toward loyalty and behavior intention.

According to the previous studies related to this study, although there may be some differences in the subject, it was argued that the involvement of Taekwondo trained children had a significant influence on loyalty [5], and it was claimed that service quality involvement of commercial sports facilities significantly affects the building and strengthening of customer loyalty, which supported the results of this study. In addition, a study that investigated the effects of relationship benefits perceived by Taekwondo training students on customer loyalty and intention to re-register [12], according to the involvement of trainees, the attitude of consumers changed and the intention to re-register was also high. Likewise, [13] studied the effect of computer school education service quality on students' intention to reregister. As a result, the involvement of value, interest, and perceived relevance was said to be an essential factor to prevent negative word of mouth or conversion intention.

In order to activate marine leisure sports, it is necessary to analyze the activities related to participation involvement pursued by the participants. However, by simply measuring the analysis of participation involvement, it is highly likely that it will not be possible to understand the psychological aspects of marine leisure sports participants, and will result in an ineffective marketing strategy. Therefore, it is judged that the detailed examination of participation involvement, loyalty, and behavior intention will help in the qualitative development and activation of increased participation in marine leisure sports.

\section{Conclusion}

This study was conducted to investigate the relationship between participation involvement, loyalty and behavior intention of marine leisure sports participants, and the conclusions obtained through the research process are as follows.

First, participation involvement of marine leisure sports participants showed a positive correlation with all loyalty, while behavior intention partially showed a positive correlation.

Second, all of the sub-variables of participation involvement had a statistically significant positive influence on all loyalty, thus attitude loyalty and action loyalty.

Third, among the sub-variables of participation involvement, participation enjoyment had a positive influence on reparticipation intention, and the participation interest had a positive influence on positive word of mouth.

As a result, it can be seen that the participation involvement of marine leisure sports participants is an important variable influencing loyalty and behavior intention. Therefore, the participation involvement of participants participating in marine leisure sports was proved to be closely related to loyalty and behavior intention in this case.

\section{Acknowledgment}

This study was from the 2019 Academic Research Support Project of Hanseo University.

\section{References}

[1] Ko, J. G. A Plan to Analyze the Property of a Latent Demand for Leisure Sports and Develop the Industr y. Korean Society of Sport Management. 2005; 10(1): 65-79.

[2] Lee, K. M., \& Kim, J. Influence of motives of club members to marine sports on participants satisfaction. Korean journal of physical education. 2007; 46(2):, 117-130.

[3] Water Leisure Safety Act. Definition of Water Leisure Activities. Maritime Police Agency;1999.

[4] Park, Y. B., \& Seo, S. O. A Study about the Promotion Plan of the Marine Sports Tour. The Korean Societ y of Sports Science. 2000; 9(1): 191-202.

[5] Lee, Ch. I. Effect of Involvement and Marketing Factors Satisfaction on Royalty in Children Practicing T aekwondo. Unpublished master's Dissertation, Chosun University; 2008.

[6] Park, H. N. The analysis on customer's involvement and advertising effect in food-service enterprise. U npublished doctor Dissertation, Kyunggi University; 2005.

[7] Kim, K. Y. The relationship between relationship marketing implement factors and customer loyalty of water leisure sport facilities. Unpublished doctor Dissertation, Kyunghee University; 2008.

[8] Kwon, W., \& Kim, S. K. Relationship between Recovery of Service Failure in Sports Center and Custome r Loyalty. Korean Society of Sport Management. 2011; 16(4): 111-125.

[9] Lee, B. K. The Influence of Participation Satisfaction, Re-participation and Participation Motives of Spo rts Event. Korea sport society. 2011; 9(3): 337-346.

[10] Jo, Y. J., \& Kwak, H. K. The Effect of Dance sport Participants' Service Equity Perception on Participati ve Satisfaction and Re-participation. Korea sport society. 2009; 7(1): 93-102.

[11] An, J. H., An, S. H., \& Park, K. B. The Influence of Life Style and Participation Motive of Participants in 
Water-Skiing on their reuse. The Korean Society of Sports Science. 2010; 19(4): 199-210.

[12] Han, K. S., \& Yang, C. H. A Study on the Relationship between Leisure Identity and Psychological Wellbeing of Members of Sports for All. The Korea Journal of Sport. 2017; 15(3): 21-29.

[13] Oh, H. O. Relationship Among the Self-determination, Psychological well-being, Satisfaction and Beha vioral intention of Pilates participants. Journal of Korean Physical Education Association for Girls and Women. 2019; 33(4): 63-81. 